\title{
Keragaan Stek Pucuk Syzygium oleina terhadap Pemberian Zat Pengatur Tumbuh Rootone-F dan Komposisi Media Tanam
}

\author{
Performance of Syzygium oleina (Red Lip) Shoot Cuttings as Affected by \\ Application of Plant Growth Regulator Rootone-F and Composition of \\ Growing Media
}

\author{
Deselina*, M. Fajrin Hidayat dan Ganesya Wiratama \\ Jurusan Kehutanan Fakultas Pertanian UNIB \\ *:deselina@ymail.com
}

\begin{abstract}
This study aims to determine the concentration of plant growth regulator combination Rootone $F$ and a growing medium that provides the best growth of Pucuk Merah shoot cuttage. The research was conducted on the July to September 2013. The method used is Complete Random Design (RAL) factorial consisting of two factors. The first factor is the concentration of plant growth regulators Rootone- $F(R)$, which consists of four levels: 0 ppm (control), $100 \mathrm{ppm}(R 1), 150 \mathrm{ppm}(\mathrm{R} 2)$ and $200 \mathrm{ppm}$ (R3). The second factor is the composition of the growing medium consists of: ground (M1), soil, sand (1: 1) (M2), soil: sand: compost (1: 1: 1) (M3). The variables measured were successful life cuttage, leaf number, root length, number of secondary roots and dry weight of cuttings and environmental factors (temperature and humidity). Results of analysis of variance showed that the concentration of plant growth regulators Rootone-F only real impact on the number of secondary roots while growing medium treatment showed no real effect on all observed variables. Combination treatment of concentration of growth regulators Rootone-F and planting media show no real effect on all observed variables. The ambient temperature during the study was ${ }^{\circ} \mathrm{C}$ 27.85-30.47 and humidity 93.48-96.32\%. Based on the results of analysis show that the combined treatment P2M2 gives the average percentage of success alive and rooted cuttings highest 73.3\%, number of leaves 2 strands, $4.07 \mathrm{~cm}$ root length, 2 number of secondary roots and root dry weight $0.56 \mathrm{~g}$.
\end{abstract}

Key words: shoot cuttage, plant growth regulator, media.

\begin{abstract}
ABSTRAK
Penelitian ini bertujuan untuk menentukan kombinasi konsentrasi zat pengatur tumbuh Rootone F dan media tanam yang memberikan pertumbuhan stek pucuk Pucuk Merah yang terbaik. Penelitian ini dilaksanakan pada Bulan Juli-September 2013. Metode penelitian yang digunakan adalah Rancangan Acak Lengkap (RAL) factorial yang terdiri dari dua faktor. Faktor pertama adalah konsentrasi zat pengatur tumbuh Rootone-F (R) yang terdiri dari empat taraf : 0 ppm (control), 100 ppm (R1), 150 ppm (R2) dan 200 ppm (R3). Faktor kedua yaitu komposisi media tanam terdiri dari : tanah (M1), tanah : pasir (1:1) (M2), tanah : pasir : kompos (1:1:1) (M3). Variabel yang diamati adalah keberhasilan stek hidup, jumlah daun, panjang akar, jumlah akar sekunder dan berat kering stek dan factor lingkungan (suhu dan kelembaban udara). Hasil analisis keragaman menunjukkan bahwa perlakuan konsentrasi zat pengatur tumbuh Rootone-F hanya berpengaruh nyata terhadap jumlah akar sekunder sedangkan perlakuan media tanam menunjukkan pengaruh tidak nyata terhadap semua variabel yang diamati. Kombinasi perlakuan konsentrasi zat pengatur tumbuh Rootone-F dan media tanam menunjukkan pengaruh tidak nyata terhadap seluruh variabel yang diamati. Suhu lingkungan selama penelitian adalah $27.85-30.47{ }^{\circ} \mathrm{C}$ dan kelembaban udara 93.48-96.32\%. Berdasarkan hasil analisis diketahui bahwa kombinasi perlakuan $\mathrm{P}_{2} \mathrm{M}_{2}$ memberikan rerata persentase keberhasilan stek hidup dan berakar tertinggi $73.3 \%$, jumlah daun 2 helai, panjang akar $4.07 \mathrm{~cm}$, jumlah akar sekunder 2 akar dan berat kering $0.56 \mathrm{~g}$.
\end{abstract}

Kata kunci : Keragaan, stek pucuk, ZPT Rootone-F, Komposisi Media Tanam. 


\section{PENDAHULUAN}

Pucuk Merah atau dengan nama latin Syzygium oleina merupakan salah satu jenis tanaman tropis yang saat ini tengah populer di Indonesia. Tanaman ini dinamakan Pucuk Merah karena memiliki daun muda yang berwarna merah. Pucuk Merah memiliki berarapa manfaat yaitu sebagai border atau pembatas atau jalur hijau, sebagai tanaman hias dalam pot, sebagai focal point pada taman bertema tropis dan sebagai tanaman pengarah. Selain memiliki daun muda yang berwarna merah. Pucuk Merah juga memiliki daun tua yang berwarna hijau yang membuat tanaman ini semakin diminati oleh pecinta tanaman hias.

Pucuk Merah dapat berkembang biak secara generatif dengan menggunakan biji. Perbanyaan dengan biji memerlukan waktu yang lebih lama. Mengingat permintaan pasar yang cukup tinggi terhadap Pucuk Merah ini maka dipilih teknik perbanyakan tanaman secara vegetatif. Pembiakan vegetative sangat diperlukan karena bibit hasil perbanyakan secara vegetatif merupakan duplikat induknya (Adinugraha $d k k, 2007$ ). Disamping itu teknik perbanyakan vegetatif mempunyai kelebihan yaitu mudah diperbanyak secara masal dalam waktu relatif singkat (Mashudi, 2013) .

Teknik perbayakan vegetatif yang dipakai pada tanaman Pucuk Merah adalah dengan menggunakan stek. Teknik perbanyakan vegetatif dengan menggunakan stek adalah metode perbanyakan tanaman dengan menggunakan bagian tanaman yang dipisahkan dari induknya, di mana jika ditanam pada kondisi yang menguntungkan untuk beregenerasi akan berkembang menjadi tanaman yang sempurna. Bagian yang paling cocok untuk dijadikan stek adalah bagian pucuk. Pucuk juga merupakan sumber auksin pada tanaman (Dwidjoseputro, 1990).

Faktor-faktor yang mempengaruhi keberhasilan stek berakar adalah sumber bahan stek dan perlakuan terhadap bahan stek (Danu dan Nurhasybi, 2003). Hal yang perlu diperhatikan dalam perlakuan terhadap bahan stek adalah penggunaan hormon tumbuh dan penggunaan jenis media tanam. Untuk mempercepat perakaran pada stek maka perlu diberikan hormon dari luar dengan memperhatikan jumlah dan konsentrasinya agar didapatkan system perakaran yang baik dalam waktu relative singkat.

Untuk perakaran stek, hormon yang paling menentukan adalah kelompok auksin. Hormon ini secara alami sudah terdapat dalam tanaman akan tetapi untuk lebih mempercepat proses perakaran stek maka perlu ditambahkan dalam jumlah dan konsentrasi tertentu untuk dapat merangsang perakaran (Yasman dan Smith, 1988). Salah satu produk komersial yang mengandung zat pengatur tumbuh auksin dan banyak digunakan adalah Rootone-F.

Media tanam yang biasa digunakan pada awal pertumbuhan stek adalah pasir. Pasir memiliki tekstur dan aerasi yang cocok bagi pertumbuhan akar namun pasir 
tidak memiliki kandungan unsur hara yang diperlukan bagi pertumbuhan lanjutan sehingga harus dilakukan penyapihan sampai bibit siap tanam. Untuk itu perlu dicari komposisi media lain sebagai campuran pasir yang memiliki aerasi yang baik dan mengandung unsur hara yang dibutuhkan oleh stek.

Tujuan dari penelitian ini adalah untuk menentukan konsentrasi Rootone-F dan media tanam yang memberikan pertumbuhan terbaik bagi stek pucuk Pucuk Merah.

\section{METODE PENELITIAN}

Penelitian ini dilaksanakan pada Bulan Juli-September 2013 di Persemaian CV. Dua Putra Sejati di Jalan Hibrida V Kota Bengkulu. Peralatan yang digunakan dalam penelitian ini adalah : gunting stek, cutter, hand sprayer, pisau, bambu, plastik sungkup, pita ukur, gelas ukur, timbangan analitik, polybag, sendok, ember, alat tulis dan kamera. Bahan yang digunakan adalah ZPT Rootone-F, aquades, stek pucuk Pucuk Merah orthotrop yang telah berumur dua tahun, tanah topsoil, pasir, kompos, fungsida Dithane M-45.

Pelaksanaan penelitian dilaksanakan melalui beberapa tahapan kegiatan yaitu : penyiapan media tanam, pembuatan sungkup, pemilihan bahan stek, penyiapan larutan Zat Pengatur Tumbuh Rootone-F serta penanaman dan pemeliharaan stek pucuk.

Media tanam yang digunakan adalah tanah, tanah : pasir sungai (1:1), tanah : pasir sungai : kompos (1:1:1). Tanah yang digunakan adalah tanah topsoil yang diambil di lokasi persemaian CV. Dua Putra Sejati. Media pasir berasal dari pasir sungai. Tanah dan pasir tesebut disterilisasi dengan cara disangrai. Kompos yang dipergunakan dalam penelitian ini dibeli di toko sarana pertanian dengan kandungan Nitrogen 1-2\%, Phosphor 0.75-2\%, Kalium 3-5\%, Magnesium 1-1.5\%, C-Organik 27.5-32\%, Kelembaban 14.75-20\%, pH 6.5-7.5, C-N rasio 15-25.

Sungkup dibuat dari potongan bambu sesuai ukuran sungkup (panjang $1.5 \mathrm{~m}$, lebar $1.25 \mathrm{~m}$ dan tinggi $30 \mathrm{~cm}$ ). Selanjutnya potongan bambu tersebut disusun sesuai dengan kerangka sungkup, kemudian ditutup dengan plastik transparan. Sungkup siap digunakan.

Bahan stek yang dipilih bersifat orthotrop dari pohon induk yang berumur 2 tahun. Panjang stek yang diambil sebagai bahan stek adalah 10-15 $\mathrm{cm}$ atau sepanjang 3 nodus dan dipotong tepat di bawah tangkai daun (nodum). Daun-daun pada stek digunting hingga tersisa $1 / 3$ bagian daun. Pangkal stek selanjutnya dipotong miring dengan sudut pemotongan $45^{\circ} \mathrm{C}$.

Larutan ZPT dibuat dengan cara menimbang ZPT Rootone-F yang kemudian diberi beberapa tetes Alkohol 95\% yang dicampur aquades untuk dijadikan larutan dengan level konsentrasi sebagai berikut :

a. Konsentrasi 0 ppm (tanpa Rootone-F)

b. Konsentrasi 100 ppm, adalah campuran 100 mg Rootone-F dengan 1 liter 
Aquades

c. Konsentrasi 200 ppm, adalah campuran $100 \mathrm{mg}$ Rootone-F dengan 1 liter Aquades

d. Konsentrasi 300 ppm, adalah campuran $100 \mathrm{mg}$ Rootone-F dengan 1 liter Aquades

Stek pucuk direndam dalam larutan ZPT setinggi $2 \mathrm{~cm}$ dari pangkal stek selama 1 jam.

1. Penanaman

Stek pucuk ditanam dengan membuat lubang tanam sedalam $2 \mathrm{~cm}$ pada polybag yang ditempatkan di bawah sungkup. Setelah semua stek ditanam selanjutnya dilakukan penyiraman.

2. Pemeliharaan Stek Pucuk.

Pemeliharaan dilakukan dengan menyiram stek secara rutin setiap 3 hari. Penyiangan dilakukan terhadap rumput yang tumbuh dan penyemprotan fungisida Dithane M-45 apabila terdapat gejala serangan jamur.

Rancangan yang digunakan dalam penelitian ini adalah Rancangan Acak Lengkap yang disusun secara faktorial dengan dua faktor, yaitu Konsentrasi ZPT Rootone F dan Jenis Media.

Faktor Konsentrasi ZPT Rootone-F terdiri dari 4 taraf, yaitu : $\mathrm{R}_{0}=$ konsentrasi $0 \mathrm{ppm}, \mathrm{R}_{1}=$ konsentrasi $100 \mathrm{ppm}, \mathrm{R}_{2}=$ konsentrasi $150 \mathrm{ppm}, \mathrm{R}_{3}=$ konsentrasi 200 ppm. Faktor Jenis Media terdiri dari 3 jenis yaitu : $M_{1}=$ tanah, $M_{2}=$ tanah : pasir sungai $(1: 1), M_{3}=$ tanah : pasir sungai : $\operatorname{kompos}(1: 1: 1)$,
Variabel yang diamati dalam penelitian ini adalah :

1. Persentase Keberhasilan Stek

Persentase Keberhasilan Stek dihitung dengan rumus :

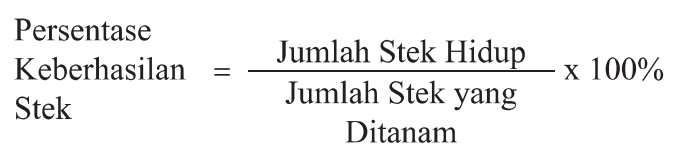

2. Pertambahan Jumlah Daun

Jumlah daun dihitung saat daun telah terbentuk sempurna yang bertambah pada setiap stek.

3. Panjang Akar

Panjang akar stek yaitu panjang akar yang terbentuk dari setiap stek dengan menghitung akar terpanjang.

4. Jumlah Akar Lateral

Jumlah akar lateral yaitu jumlah akar lateral yang terbentuk dari setiap stek di akhir pengamatan.

5. Berat Kering Total

Berat kering diukur dengan menimbang stek yang telah dikeringkan menggunakan oven dengan suhu $80{ }^{\circ} \mathrm{C}$ selama 2 x 24 jam terlebih dahulu.

Data penunjang meliputi data suhu $\left({ }^{\circ} \mathrm{C}\right)$ dan kelembaban udara (\%) harian dalam sungkup pada pagi, siang dan sore hari selama penelitian. Data hasil pengamatan dianalisis menggunakan analisis sidik ragam dengan taraf uji 5\%. Bila pengaruh perlakuan menunjukkan pengaruh yang berbeda nyata terhadap variable yang diamati maka dilanjutkan dengan Uji Jarak Berganda Duncan (DMRT)pada taraf sig- 
nificant 5\% (Gomez dan Gomez, 1995). Model linier yang digunakan adalah $\mathrm{Y}_{\mathrm{ijk}}=$ $\mu+\mathrm{P}_{\mathrm{i}}+\mathrm{K}_{\mathrm{j}}+(\mathrm{PK})_{\mathrm{ij}}+€_{\mathrm{ijk}}$

Keterangan :

Yijk $=$ nilai pengamatan

$\mu \quad=$ nilai tengah populasi

$\mathrm{P}_{\mathrm{i}} \quad=$ pengaruh faktor $\mathrm{P} \mathrm{ke}-\mathrm{i}$

$\mathrm{K}_{\mathrm{j}} \quad=$ pengaruh faktor $\mathrm{M} \mathrm{ke-j}$

$(\mathrm{PK})_{\mathrm{ij}}=$ pengaruh interaksi antara faktor $\mathrm{P}$ ke-i dan faktor K ke-j

$€_{\mathrm{ijk}}=$ galat percobaan

\section{HASIL DAN PEMBAHASAN}

Berdasarkan hasil pengamatan keberhasilan stek pucuk hidup dan berakar dari 36 unit percobaan adalah 67.22\%. Jumlah stek yang hidup adalah 240 stek dari 360 stek yang ditanam. Nilai persentase tertinggi didapat pada kombinasi perlakuan $\mathrm{R}_{1} \mathrm{M}_{2}$ yaitu $76.7 \%$ sedangkan persentase terendah yaitu $56.7 \%$ didapat pada perlakuan $\mathrm{R}_{1} \mathrm{M}_{2}$ dan $\mathrm{R}_{3} \mathrm{M}_{1}$. Rata-rata persentase keberhasilan stek hidup dapat dilihat pada Gambar 1.

Berdasarkan hasil analisis keragaman yang diperlihatkan pada Tabel 1 didapat bahwa perlakuan konsentrasi Rootone-F hanya berpengaruh nyata terhadap jumlah akar lateral, sedangkan perlakuan komposisi media tanam berpengaruh tidak nyata terhadap semua variabel yang diamati. Interaksi perlakuan konsentrasi Rootone-F dan komposisi media tanam berpengaruh tidak nyata terhadap semua variabel yang diamati. Hasil analisis keragaman (nilai $\mathrm{F}$ hitung) setiap variabel pengamatan pertumbuhan stek pucuk merah disajikan pada Tabel 1. Rerata keberhasilan stek pucuk merah pada pemberian konsentrasi ZPT Rootone-F disajikan pada Gambar 2 sedangkan rerata keberhasilan stek pucuk merah pada berbagai komposisi media tanam disajikan pada Gambar 3.

Pengaruh pemberian konsentrasi Rootone-F terhadap stek hidup menunjukkan bahwa dengan adanya pemberian konsentrasi Rootone-F keberhasilan stek hidup pucuk merah pada pemberian konsentrasi 0 ppm $\left(\mathrm{R}_{0}\right), 100 \mathrm{ppm}\left(\mathrm{R}_{1}\right), 150 \mathrm{ppm}\left(\mathrm{R}_{2}\right)$ cenderung memiliki rerata keberhasilan stek yang sama sedangkan pada perlakuan 200 ppm $\left(\mathrm{R}_{3}\right)$ memiliki rerata keberhasilan stek hidup yang paling rendah dibanding dengan yang lainnya.

Wudianto (1995) menjelaskan bahwa penambahan ZPT pada konsentrasi yang tepat dapat menstimulir tunas dan akar stek. Zat Pengatur Tumbuh Rootone-F termasuk dalam kelompok auksin. Secara teknis Rootone-F sangat aktif mempercepat dan memperbanyak keluarnya akar sehingga penyerapan air dan unsure hara tanaman akan banyak dan dapat mengimbangi penguapan air pada bagian tanaman yang berada di atas tanah. Salisbury dan Ross (1995) menjelaskan bahwa auksin mengaktifkan beberapa enzim yang dapat memutuskan ikatan polisakarida dinding sel tanaman sehingga menyebabkan dinding sel merenggang dan lebih permiabel untuk masuknya air ke dalam sel.

Menurut Kusumo (1984) perakaran 
Tabel 1. Hasil analisis keragaman (nilai $\mathrm{F}$ hitung) setiap variable pengamatan pertumbuhan stek pucuk merah

\begin{tabular}{llccc}
\hline No & Variabel & $\begin{array}{c}\text { Konsentrasi } \\
\text { rootone-F }\end{array}$ & Jenis media tanam & Interaksi \\
\hline 1. & Keberhasilan Stek & $0.66 \mathrm{~ns}$ & $0.72 \mathrm{~ns}$ & $0.76 \mathrm{~ns}$ \\
2. & Jumlah Daun & $1.81 \mathrm{~ns}$ & $0.15 \mathrm{~ns}$ & $1.21 \mathrm{~ns}$ \\
3. & Panjang Akar & $2.05 \mathrm{~ns}$ & $2.05 \mathrm{~ns}$ & $0.49 \mathrm{~ns}$ \\
4. & Jumlah Akar Lateral & $3.13^{*}$ & $1.31 \mathrm{~ns}$ & $1.34^{\mathrm{ns}}$ \\
5. & Berat Kering & $0.47 \mathrm{~ns}$ & $0.23 \mathrm{~ns}$ & $0.31^{\mathrm{ns}}$ \\
\hline
\end{tabular}

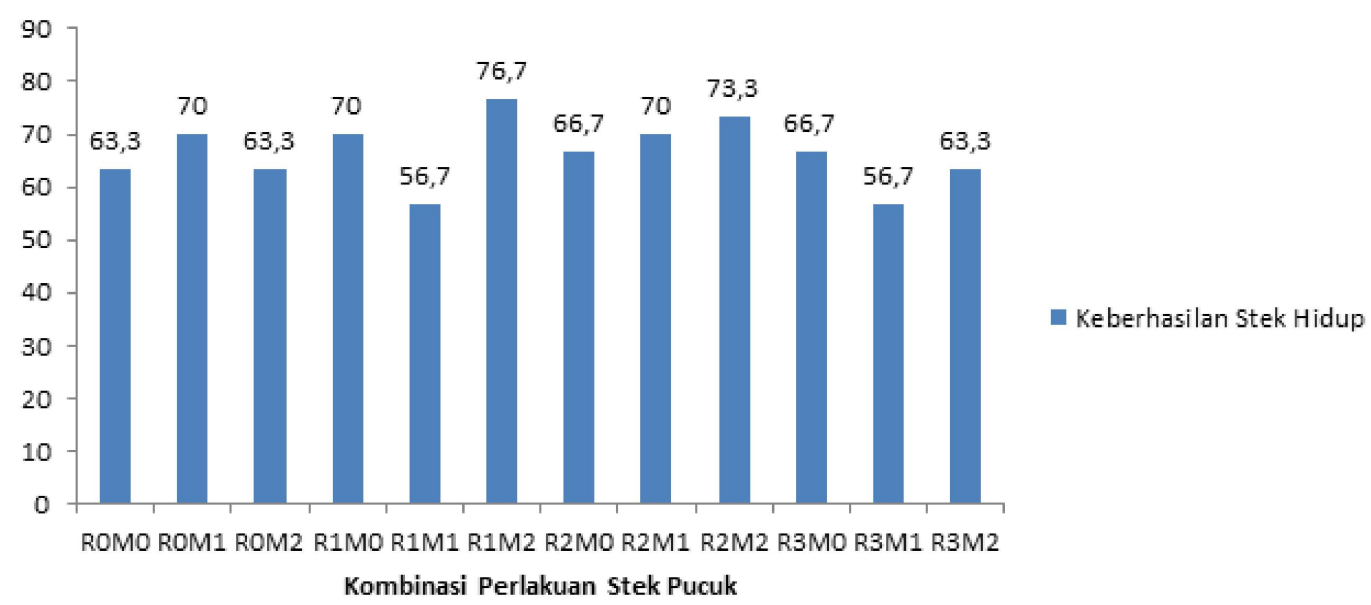

Gambar 1. Rata-rata persentase keberhasilan stek hidup (\%) pada masing-masing kombinasi perlakuan

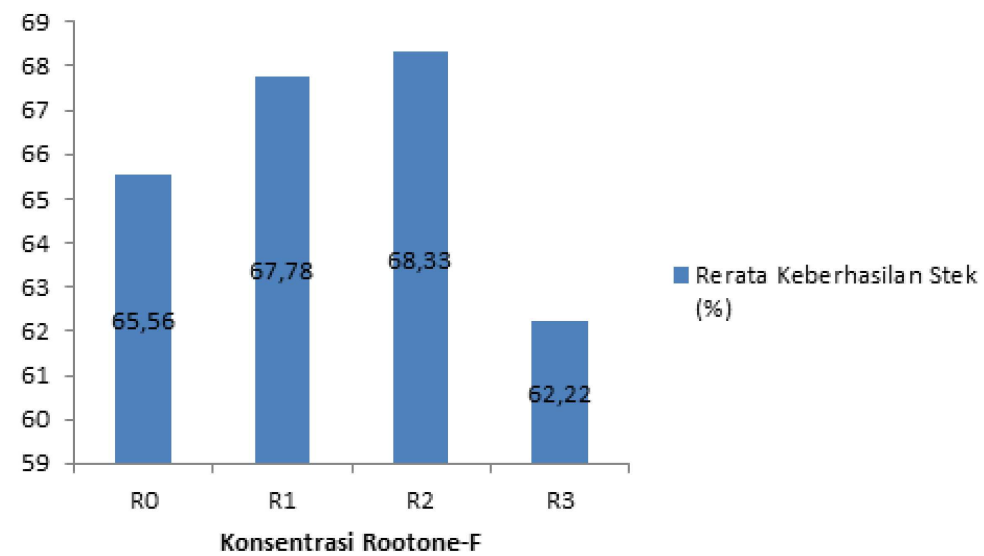

Gambar 2. Rata-rata persentase keberhasilan stek hidup (\%) pada pemberian konsentrasi ZPT Rootone-F 


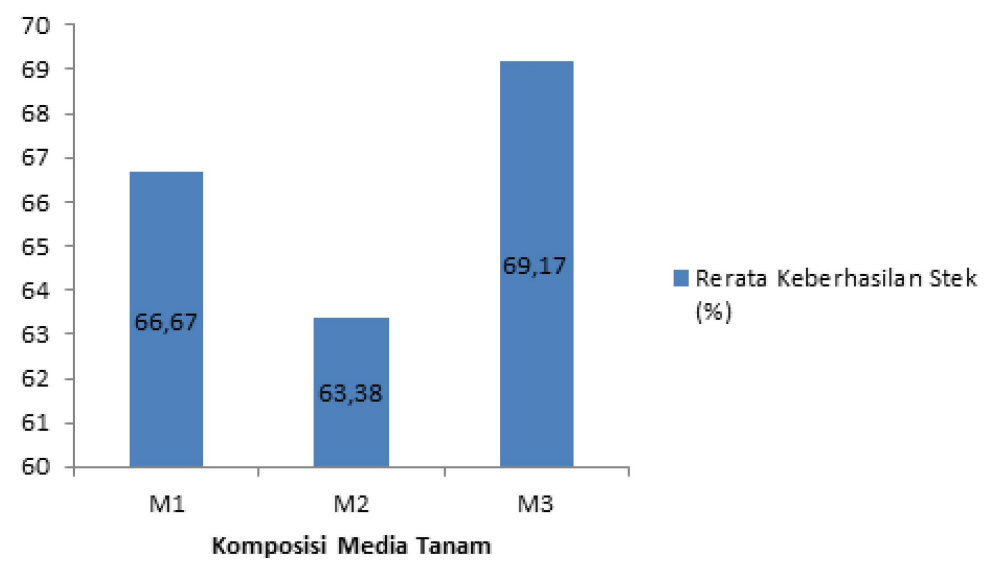

Gambar 3. Rata-rata persentase keberhasilan stek hidup (\%) pada komposisi media tanam yang timbul pada stek disebabkan dorongan auksin yang berasal dari daun, tunas dan zat pengatur tumbuh yang berasal dari luar. Tunas yang sehat pada batang adalah sumber auksin dan merupakan factor penting dalam perakaran. Salisbury dan Ross (1995) menambahkan bahwa sel akar umumnya mengandung cukup atau hamper cukup auksin untuk memanjang secara normal. Kebutuhannya akan hormone sudah terpenuhi dari hasil sintesis tanaman itu sendiri. Sementara itu Utami (2001) mengatakan bahwa terbentuknya stek adalah karena zat pengatur tumbuh auksin yang dihasilkan oleh tunas dan daun yang ditranslokasikan ke bawah melalui floem dan tertahan pada dasar stek.

Berdasarkan Tabel 1 menunjukkan bahwa perlakuan pemberian konsentrasi ZPT Rootone-F berpengaruh nyata terhadap jumlah akar lateral. Hasil uji lanjut pengaruh konsentrasi ZPT Rootone-F terhadap pertumbuhan stek pucuk merah disajikan pada Tabel 2 sedangkan rerata jumlah akar lateral pada masing-masing konsentrasi Rootone-F disajikan pada Gambar 4.

Pertumbuhan akar lateral stek akan optimal apabila kondisi lingkungan juga optimal karena akan menentukan aktivitas hormonal yang terdapat pada batang dalam mendorong keluarnya akar . Pemakaian zat pengatur tumbuh tidak dapat menggantikan keadaan lingkungan yang baik untuk perakaran stek. Jika keadaan lingkungan diabaikan, pemakaian zat pengatur tumbuh tidak akan membantu keluarnya akar pada stek (Masano $d k k, 1997)$.

Pemberian konsentrasi ZPT Rootone-F 200 ppm cenderung menurunkan rerata jumlah akar lateral yang berbeda nyata pada konsentrasi 150 ppm. Ini menunjukkan bahwa kadar auksin yang tinggi lebih berperan menekan pertumbuhan daripada merangsangnya. Salisbury dan Ross (1995) menambahkan bahwa sel akar umumnya mengandung cukup atau hamper cukup auksin untuk memanjang secara normal. 
Tabel 2. Hasil uji lanjut pengaruh konsentrasi ZPT Rootone-F terhadap pertumbuhan stek pucuk merah

\begin{tabular}{cccc}
\hline Perlakuan & $\begin{array}{c}\text { Konsentrasi ZPT } \\
\text { rootone-F }\end{array}$ & $\begin{array}{c}\text { Rata-rata jumlah akar } \\
\text { sekunder }\end{array}$ & DMRT 5\% \\
\hline $\mathrm{R}_{2}$ & $150 \mathrm{ppm}$ & 1.772 & $\mathrm{c}$ \\
$\mathrm{R}_{0}$ & $0 \mathrm{ppm}$ & 1.718 & $\mathrm{c}$ \\
$\mathrm{R}_{3}$ & $200 \mathrm{ppm}$ & 1.333 & $\mathrm{ab}$ \\
$\mathrm{R}_{1}$ & $100 \mathrm{ppm}$ & 1.149 & $\mathrm{a}$ \\
\hline
\end{tabular}

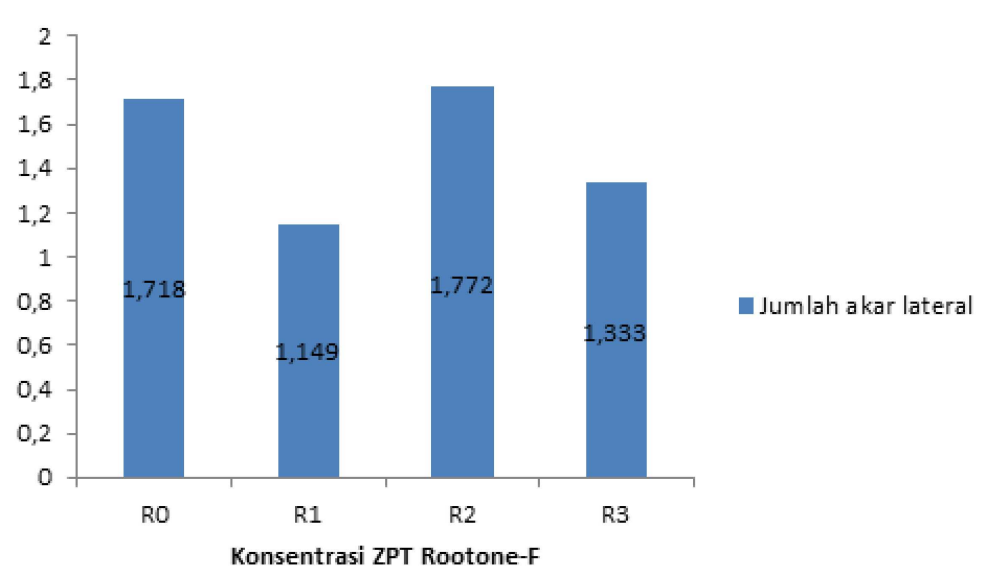

Gambar 4. Rerata jumlah akar lateral pada masing-masing konsentrasi Rootone-F

Kebutuhan akan hormone sudah terpenuhi dari hasil sintesis tanaman itu sendiri. Perpanjangan akar stek akan lebih terpacu bila ditambah auksin sintetis pada konsentrasi yang tepat (Kusumo, 1984).

Diduga pemberian konsentrasi ZPT Rootone-F pada 100 ppm belum optimum untuk meningkatkan proses pembelahan pada jaringan meristem yang dapat meningkatkan pertumbuhan tunas dan bakal akar yang terbentuk. Kusumo (1990) berpendapat bahwa zat pengatur tumbuh akan efektif pada konsentrasi tertentu, sependapat dengan Harjadi (1991) bahwa kecepatan pertumbuhan tunas dan akar pada stek juga dipengaruhi konsentrasi
ZPT yang diberikan. Pemberian ZPT pada konsentrasi optimum sangat dibutuhkan untuk merangsang pertumbuhan tunas dan akar sementara pemberian ZPT di bawah konsentrasi optimum akan menjadi tidak efektif dalam memacu pertumbuhan akar (Wudianto, 1993).

Pemberian konsentrasi ZPT Rootone-F 150 ppm diduga mampu memberikan rerata teringgi terhadap jumlah akar lateral stek pucuk Pucuk Merah dibandingkan dengan tingkat konsentrasi lainnya pada akhir penelitian. Belum nampaknya keberhasilan stek pucuk Pucuk Merah yang tumbuh secara optimum diduga karena singkatnya waktu pengamatan. 
Keberhasilan stek hidup dan berakar pada penelitian ini adalah $66.67 \%$. Hal ini diduga oleh faktor lingkungan dalam hal ini suhu dan kelembaban serta kondisi fisiologis stek. Pada penelitian ini kondisi kelembaban dan suhu dalam sungkup berturut-turut $85-100 \%$ dan $28-34{ }^{\circ} \mathrm{C}$. Selain itu sifat fisik pada media juga berpengaruh terhadap perkembangan akar tanaman, karena sifat fisik tersebut akan mempengaruhi kelancaran gerakan air dan udara dalam media sehingga ketersediaan oksigen bagi perkembangan akar menjadi cukup tersedia. Jenis media tanam $\mathrm{M}_{2}$ memiliki kerberhasilan stek hidup yang paling tinggi (Gambar 3). Hal ini diduga karena $\mathrm{M}_{2}$ memiliki porositas yang cukup tinggi dan hara yang lebih baik dibanding dengan $\mathrm{M}_{0}$ dan $\mathrm{M}_{1}$.

Ketidakberhasilan stek dalam membentuk akar diduga karena faktor lingkungan seperti suhu. Suhu dalam sungkup berfluktuasi dari $28-34{ }^{\circ} \mathrm{C}$. Suhu yang tinggi pada siang hari dan kelembaban yang relatif rendah menyebabkan proses transpirasi semakin cepat dan pembentukan akar berlangsung lambat sehingga tanaman menjadi layu dan mati. Suhu yang terlalu tinggi dapat mendorong perkembangan tunas melampaui perkembangan perakaran dan meningkatkan laju transpirasi (Hartman dan Kester, 1983).

Hasil analisis keragaman terhadap masing-masing variabel pengamatan menunjukkan bahwa perlakuan media tanam berpengaruh tidak nyata terhadap semua variabel. Tidak nyatanya pengaruh terhadap semua variable pengamatan pada perlakuan komposisi media tanam diduga karena karakteristik stek pucuk Pucuk Merah yang dapat tumbuh pada ketiga komposisi media tanam tersebut.Siagian dan Adinugraha (2001) menjelaskan bahwa pengaruh media tanam tidak terlihat nyata selama media tersebut memenuhi syarat terhadap pertumbuhan tanaman.

Berdasarkan hasil analisis keragaman diketahui bahwa tidak terdapat interaksi antara pemberian ZPT Rootone-F dan komposisi media tanam terhadap pertumbuhan stek pucuk Pucuk Merah pada semua variabel yang diamati. Tidak nyatanya pengaruh interaksi antara konsentrasi Rootone-F dan komposisi media tanam diduga karena sifat genetis pucuk merah dapat tumbuh cepat dan baik pada berbagai jenis tanah.

Kombinasi perlakuan $\mathrm{R}_{2} \mathrm{M}_{2}$ memberikan hasil yang paling baik terhadap semua variabel yang diamati meliputi keberhasilan stek $73.3 \%$, jumlah daun 2 helai, panjang akar $4.07 \mathrm{~cm}$, jumlah akar lateral 2 akar dan berat kering $0.56 \mathrm{~g}$. Peningkatan konsentrasi menjadi $\mathrm{R}_{3}(200 \mathrm{ppm})$ diduga cenderung menurunkan rata-rata semua variabel pengamatan meliputi keberhasilan stek, jumlah daun, panjang akar lateral dan berat kering. Menurut Isbandi (1983) bahwa kadar auksin yang tinggi lebih berperan menekan pertumbuhan daripada merangsangnya. Salisbury dan Ross (1995) menambahkan bahwa sel akar umumnya 
mengandung cukup atau hampir cukup auksin untuk memanjang secara normal. Kebutuhan akan hormon sudah terpenuhi dari hasil sintesis tanaman itu sendiri. Perpanjangan akar stek akan lebih terpacu bila ditambah auksin sintetis pada konsentrasi yang tepat (Kusumo, 1984).

Kondisi bahan stek yang beragam dan terbatasnya waktu pengamatan menyebabkan tidak nyatanya pengaruh pemberian konsentrasi ZPT Rootone-F dan komposisi media tanam terhadap pertumbuhan stek pucuk Pucuk Merah. Bahan stek dalam pertumbuhannya berada dalam proses perkembangan untuk menumbuhkan akar, di mana dalam proses tersebut unsur hara tersedia telah tersedia dalam stek untuk menumbuhkan dan memanjangkan akar yang ada.

\section{KESIMPULAN}

Pengaruh kombinasi konsentrasi zat pengatur tumbuh Rootone-F dan komposisi media tanam tidak berpegaruh terhadap variabel kekerhasilan stek hidup, jumlah daun, panjang akar dan berat kering total. Kombinasi perlakuan $\mathrm{P}_{2} \mathrm{M}_{2}$ memberikan rerata persentase keberhasilan stek hidup dan berakar tertinggi $73.3 \%$, jumlah daun 2 helai, panjang akar $4.07 \mathrm{~cm}$, jumlah akar sekunder 2 akar dan berat kering $0.56 \mathrm{~g}$.

\section{DAFTAR PUSTAKA}

Adinugraha, HA., S. Pudjiono dan D. Yudistiro. 2007.Pertumbuhan stek pucuk dari tunas hasil pemangkasan semai jenis Eucalyptus pellita F. Muell di persemaian. Jurnal Pemuliaan Tanaman Hutan No.1 Juli 2007. Balai Besar Penelitian Bioteknologi dan Pemuliaan Tanaman Hutan.

Danu dan Nurhasybi, 2003. Pengaruh bahan stek dan zat pengatur tumbuh terhadap pertumbuhan stek sungkai (Peronema canescens JACK). Balai Penelitian dan Pengembangan Kehutanan. Departemen Kehutanan. Bogor.

Dwidjoseputro, D/. 1990. Pengantar Fisiologi Tumbuhan. PT. Gramedia, Jakarta.

Gomez, KA dan AA. Gomez. 1995. Prosedur Statistik untuk Penelitian Pertanian. Edisi Kedua. Penerbit Universitas Indonesia, Jakarta (Terjemahan oleh E. Sjamsuddin dan JS. Baharsjah).

Harjadi, SS. 1989. Dasar-dasar Hortikultura. Jurusan Budidaya Pertanian. Fakultas Pertanian. Institut Pertanian Bogor, Bogor.

Harjadi, MMSS, 1991. Pengantar Agronomi, PT. Gramedia, Jakarta.

Hartman, HT dan DE. Kester. 1983. Plant Propagation Principles and Practice. Prentice Hall Inc. New Jersey.

Isbandi, D, 1983. Pertumbuhan dan Perkembangan Tanaman. Fakultas Pertanian Universitas Gadjah Mada, Yogyakarta.

Kusumo, 1984. Zat Pengatur Tumbuh. CV Yasaguna, Jakarta. 
Masano, Y., Y. Sumarna, Mindawati, SA Kosasih. 1997. Sistem dan struktur perakaran stek pucuk meranti. Balai Penelitian dan Pengembangan Kehutanan.

Mashudi, 2013. Pengaruh provenan dan komposisi media tanam terhadap keberhasilan teknik penunasan pada stek pucuk Pulai Darat. Jurnal Penelitian Hutan Tanaman vol 10 no.1, Maret 2013 : 25-32.

Salisbury, FB dan CW Ross.1995. Fisiologi Tumbuhan. Penerbit ITB Bandung.

Utami, NV, 2001. Perbanyakan bibit Podocarpus spp. Dengan pemberian Zat Pengatur Tumbuh : IBA, NAA, IAA dan 2.4 D. LIPI. Jakarta.

Wudianto, R. 1993. Membuat Stek, Cangkok dan Okulasi. Penerbit PT. Pene- bar Swadaya, Jakarta.

Siagiaan, YT dan HA. Adinugraha, 2001. Daya pertunasan cabang dan keberhasilan stek pucuk jenis Melaleuca cajuputi sub.sp.cajuputi pada beberapa macam media. Buletin Penelitian Pemuliaan Pohon 5 (2) : 12-30.

Sofyan, A dan I. Muslimin, 2007. Pengaruh bahan dan media stek terhadap pertumbuhan stek batang Tembesu (Fragea fragrans ROXB). Prosiding Ekspose Hasil-hasil Penelitian : Konservasi dan Rehabilitasi Sumberdaya Hutan, Padang.

Yasman, I. dan WTM. Smiths. 1988. Metode Pembuatan Stek Dipterocarpaceae. Balai Penelitian Kehutanan, Samarinda. 